\title{
MAHASISWA BEKERJA DAN DAMPAKNYA PADA AKTIVITAS BELAJAR DAN PRESTASI AKADEMIK
}

\author{
Elma Mardelina \& Ali Muhson \\ Universitas Negeri Yogyakarta, Indonesia \\ Email: elmz.elmz@gmail.com
}

\begin{abstract}
Abstrak: Mahasiswa Bekerja dan Dampaknya Terhadap Aktivitas Belajar dan Prestasi Akademik. Penelitian bertujuan mengetahui dampak kerja part-time terhadap aktivitas belajar dan prestasi akademik mahasiswa. Populasi penelitian adalah mahasiswa S1 angkatan 2013 Fakultas Ekonomi Universitas Negeri Yogyakarta. Penelitian ini mengambil sampel sebanyak 205 responden dengan teknik propotional random sampling. Teknik pengumpulan data menggunakan kuesioner dan dokumentasi. Analisis data menggunakan metode MANOVA. Hasil penelitian menunjukkan bahwa kerja part-time memiliki pengaruh yang signifikan terhadap aktivitas belajar dan prestasi akademik. Mahasiswa yang bekerja part-time cenderung memiliki waktu yang lebih sedikit dalam aktivitas belajar dibandingkan dengan mahasiswa yang tidak bekerja. Prestasi akademik mahasiswa yang bekerja part-time juga cenderung lebih rendah dibandingkan dengan mahasiswa yang tidak bekerja.
\end{abstract}

Kata Kunci : Prestasi Akademik, Aktivitas Belajar, Mahasiswa Bekerja

\begin{abstract}
Working Student and Its Impact on Learning Activities and Academic Achievements. This study is aimed to find out the impact of part-time jobs on the learning activities and academic achievements. The population of this study is students Faculty of Economics year 2013, Yogyakarta State University. The 205 samples selected using proportional random sampling approach. Questionnaire and documentation are used to collect data. This research uses MANOVA to analyze the data. The results show that there is a significant effect of part-time jobs on the learning activities and academic achievements. The working students have a lower time for learning than the non-working students. The working students' academic achievement is lower than the non-working students.
\end{abstract}

Keywords: Academic Achievements, Learning Activities, Working Student.

\section{PENDAHULUAN}

Seiring dengan perkembangan zaman, berbagai jenis kebutuhan semakin meningkat dan kompleks. Kebutuhan yang krusial bagi manusia salah satunya, yakni kebutuhan akan pendidikan. Pendidikan merupakan kebutuhan manusia yang sangat penting karena pendidikan mempunyai tugas untuk menyiapkan SDM bagi pembangunan bangsa dan negara.

Secara rinci kebutuhan mahasiswa guna kelancaran melaksanakan pendidikan sangat beragam dan harus terpenuhi agar kebutuhannya akan pendidikan tidak terganggu, di antaranya seperti untuk membayar SPP, membeli alat tulis lengkap, membeli buku teks/buku tulis, biaya fotokopi, biaya pelatihan, biaya riset/penelitian, biaya praktek bidang studi, akses internet, dan berbagai pembiayaan lain untuk memenuhi tuntutan pendidikan khususnya di perguruan tinggi. Terlebih tambahan untuk biaya hidup mahasiswa, 
seperti: makan, kos, bensin, service motor dan lain-lain.

Kebutuhan akan hidup yang kian meningkat pula membuat mahasiswa harus mencari cara untuk mampu mencukupi kebutuhannya untuk pendidikan dan juga untuk biaya hidupnya. Beberapa mahasiswa mencari jalan keluar dengan cara bekerja. Fenomena peran ganda mahasiswa, yakni kuliah sambil bekerja sudah banyak ditemukan (Robert, 2012). Umumnya mahasiswa akan memilih bekerja dengan sistem kontrak dalam jangka pendek (shortterm contracts) dan kerja paruh waktu (parttime jobs) (van der Meer \& Wielers, 2001). Namun demikian mahasiswa akan lebih memilih kerja part-time dikarenakan lebih fleksibel dalam mengatur waktu bekerja dengan kuliah. Selain itu, bekerja part-time memiliki waktu yang lebih sedikit dari itu, biasanya per hari hanya membutuhkan waktu sekitar 3-5 jam.

Beragam alasan yang melatarbelakangi mahasiswa untuk kuliah sambil bekerja. Alasan utamanya adalah terkait dengan finansial yakni memperoleh penghasilan untuk membayar pendidikan dan kebutuhan sehari-hari sekaligus meringankan beban keluarga. Alasan lainnya adalah untuk mengisi waktu luang dikarenakan jadwal perkuliahan yang tidak padat, ingin hidup mandiri agar tidak ketergantungan dengan orang lain ataupun orang tua, mencari pengalaman di luar perkuliahan, menyalurkan hobi dan macam-macam alasan lainnya. Seperti yang dikemukakan oleh Daulay (2009: 1), bahwa mahasiswa yang kerja paruh waktu dilatarbelakangi oleh masalah ekonomi, mengisi waktu luang, hidup mandiri dan mencari pengalaman.
Sedangkan menurut Jacinta, yang mendasari seorang mahasiswa untuk bekerja di antaranya adalah kebutuhan finansial, kebutuhan sosial relasional, dan kebutuhan aktualisasi diri (Dudija, 2011: 200).

Dari penjelasan di atas, dapat diketahui bahwa alasan yang melatarbelakangi mahasiswa kuliah sambil bekerja adalah karena adanya kebutuhan akan keuangan guna membantu dalam hal perekonomian keluarga atau yang berhubungan dengan faktor ekonomi, berupa upah, gaji dan penghasilan yang didapat dari bekerja, kemudian kebutuhan sosial relasional yakni dapat berupa kebutuhan untuk bergaul dengan banyak orang sehingga akan mengenal lingkungan dan menambah teman agar mampu mengembangkan pola pikir mahasiswa dengan bertukar pikiran dengan orang banyak, selanjutnya kebutuhan aktualisasi diri yakni kebutuhan akan pengembangan diri sebagai bentuk aktualisasi diri dalam menemukan arti hidup sesungguhnya.

Di sisi lain adanya konflik peran antara kuliah dan bekerja dapat menjadi sumber stress, absensi dan produktivitas (Lenaghan \& Sengupta, 2007). Mahasiswa yang kuliah sambil bekerja dituntut untuk mampu melaksanakan tugas dan tanggung jawabnya dengan baik, mulai dari manajemen waktu antara waktu yang digunakan untuk kuliah dengan pekerjaan, kedisiplinan, baik itu dalam urusan perkuliahan maupun dalam pekerjaan, dan memperhatikan kondisi kesehatan fisik karena mereka harus membagi peran antara menjadi seorang mahasiswa dan karyawan. Menjalani kuliah sambil bekerja bukanlah hal yang mudah. Pilihan untuk kuliah sambil bekerja tentunya 
memiliki manfaat dan risiko tersendiri bagi kelangsungan pendidikan mahasiswa dan di sisi lain bekerja juga menimbulkan efek negatif bagi mahasiswa.

Manfaat yang diperoleh mahasiswa dengan bekerja selain finansial adalah untuk pengembangan keterampilan, pemahaman yang luas tentang dunia bisnis, dan peningkatan kepercayaan diri (Curtis \& Shani, 2002). Dengan bekerja, mahasiswa mampu berpikir lebih kreatif, dan memiliki jiwa profesional. Dengan demikian manfaat dari mahasiswa yang bekerja salah satunya adalah diharapkan mahasiswa mampu mengaplikasikan diri dalam kehidupan nyata sebagai hasil belajar yang didapat di bangku perkuliahan. Semua bekal tersebut tentu sangat berguna perkembangan studi, baik pada saat ini maupun di masa depan.

Selain itu, manfaat lain adalah dapat membantu orang tua dalam membiayai kuliah, memperoleh pengalaman kerja serta kemandirian ekonomis, ketrampilan akan menciptakan mahasiswa menjadi mandiri, namun banyak hal yang harus dikorbankan mahasiswa yang bekerja part-time seperti berkurangnya waktu belajar, sosialisasi dengan teman, dan waktu istirahatnya, sehingga dampak negatif yang ditimbulkan akhirnya akan dapat mempengaruhi aktivitas belajar mahasiswa dan prestasi akademik mahasiswa itu sendiri.

Waktu belajar di sini pengaruhnya terhadap mahasiswa melakukan kerja parttime adalah tersitanya waktu yang seharusnya untuk belajar digunakan untuk hal lain sehingga dapat mengganggu aktivitas belajar mahasiswa itu sendiri, dapat dilihat dari kemungkinan banyak mahasiswa yang lalai dalam mengerjakan tugas-tugas kuliahnya, tidak konsentrasinya mahasiswa pada saat kegiatan belajar-mengajar, dan lain sebagainya. Dan dikhawatirkan, mahasiswa malah keasikan bekerja sehingga mengenyampingkan kuliah, kuliahnya menjadi terbengkalai, atau bahkan drop-out karena kemungkinan kurangnya motivasi untuk menyelesaikan studi dan hasil belajar mengalami penurunan atau merasa pekerjaan yang dijalaninya sudah cukup untuk bekal mereka hidup.

Menurut Purwanto, dkk (2013: 36), berdasarkan hasil dari observasi yang dilakukan terhadap beberapa mahasiswa Program Studi Pendidikan Teknik Bangunan Jurusan Teknik Sipil FT-UNP, perbandingan nilai hasil belajar mahasiswa yang bekerja dengan tidak bekerja pada semester JanuariJuni 2012 angkatan 2008 adalah nilai mahasiswa tidak bekerja lebih tinggi dibandingkan nilai mahasiswa yang bekerja. Mahasiswa kuliah sambil bekerja ini, pengaruhnya dalam prestasi akademik pun mulai dipertanyakan.

National Center of Education Statistics (NCES) dalam Metriyana (2014: 10) juga menemukan bahwa mahasiswa yang bekerja lebih dari 16 jam ke atas memiliki pengaruh terhadap prestasi yang lebih rendah dibanding yang tidak bekerja. Menurut Gleason, 1993 dalam Metriyana (2014: 10) bahwa mahasiswa yang kuliah sambil bekerja cenderung mendapat gaji akan tinggi, memiliki kesempatan yang lebih besar untuk memperoleh pekerjaan setelah lulus, namun hal tersebut dapat mahasiswa kekurangan waktu dan sebagai hasilnya mereka menerima nilai yang lebih rendah.

Menurut Dadgar dalam Metriyana (2014: 6), dalam hasil wawancara dengan 
mahasiswa yang putus kuliah, ditemukan hasil bahwa ketidakmampuan untuk menyeimbangkan kegiatan kerja dan perkuliahan memainkan peran penting dalam tingkat dropout, hal ini menunjukkan adanya pengaruh dalam kegiatan bekerja pada mahasiswa pada pencapaian prestasi akademik mahasiswa itu sendiri. Prestasi akademik merupakan istilah yang menunjukkan suatu pencapaian atau tingkat keberhasilan tentang suatu tujuan sebagai hasil dari usaha belajar yang telah dilakukan oleh seseorang secara optimal. Prestasi akademik pun menjadi salah satu tolak ukur keberhasilan mahasiswa dalam menyelesaikan studinya di bangku kuliah.

Fenomena mengenai mahasiswa yang kuliah sambil kerja juga ditemukan di Universitas Negeri Yogyakarta (UNY) termasuk mahasiswa Fakultas Ekonomi (FE), tidak menutup kemungkinan terdapat mahasiswa yang kuliah sambil kerja atau part-time. Oleh karena itu penelitian ini berupaya untuk mengkaji bagaimana dampak yang ditimbulkan akibat aktivitas bekerja mahasiswa, khususnya terhadap aktivitas belajar dan prestasi akademik mereka. Penelitian tentang mahasiswa bekerja pernah dilakukan oleh Hipjillah \& Badriyah (2015) namun hanya terbatas pada mahasiswa yang bekerja paruh waktu saja kemudian dilihat dampaknya pada tingkat konsumsi dan prestasinya. Penelitian lain juga dilakukan oleh Dudija (2011) namun hanya terbatas pada dampaknya terhadap motivasi menyelesaikan skripsi saja. Penelitian ini mencoba untuk melakukan investigasi dampak mahasiswa bekerja secara lebih luas, tidak hanya terbatas pada prestasi belajar saja melainkan juga pada aktivitas belajarnya. Dengan demikian diharapkan akan memperoleh yang kajian yang lebih komprehensif tentang dampak mahasiswa bekerja.

\section{METODE}

Penelitian ini termasuk dalam penelitian kuantitatif yang meneliti pengaruh antara variabel terikat dan variabel bebas. Populasi dalam penelitian ini adalah seluruh mahasiswa kependidikan dan nonkependidikan jenjang strata 1 (S1) angkatan 2013 Fakultas Ekonomi Universitas Negeri Yogyakarta sejumlah 521. Sampel diambil sebanyak 205 dengan teknik proportional random sampling.

Variabel terikat dalam penelitian ini adalah aktivitas belajar dan prestasi akademik. Aktivitas belajar dalam penelitian ini adalah persepsi mahasiswa mengenai aktivitas belajar di dalam kelas baik aktivitas jasmani maupun aktivitas rohani. Aktivitas belajar diukur dari persepsi mahasiswa dari keterlibatan dalam melaksanakan tugas belajar, keterlibatan mahasiswa dalam pemecahan masalah, kemampuan bertanya kepada rekan sejawat atau dosen, usaha mencari berbagai informasi yang diperlukan untuk pemecahan masalah, keikutsertaan melaksanakan diskusi kelompok, kemampuan menilai diri sendiri dan hasilhasil yang diperolehnya, kemampuan melatih diri dalam memecahkan soal atau masalah, dan kemampuan menerapkan kesempatan yang diperoleh dalam menyelesaikan tugas atau persoalan yang dihadapinya.

Adapun variabel bebas dalam penelitian ini adalah kerja part-time. Variabel ini diukur berdasarkan status kerja mahasiswa, baik itu 
mahasiswa yang kuliah sambil bekerja maupun mahasiswa yang hanya kuliah saja.

Pengumpulan data dilakukan dengan teknik kuesioner. Untuk menjamin validitas dan reliabilitas, pengembangan instrumen dilakukan dengan mendasarkan pada konstruksi teoretis seperti yang dijelaskan sebelumnya dan mengujinya secara empirik. Pengujian validitas dilakukan dengan menggunakan analisis faktor. Hasilnya menunjukkan bahwa seluruh butir yang dikembangkan dapat mengukur konstruk dengan muatan faktor berkisar antara 0,510,76. Hasil estimasi reliabilitas juga menunjukkan hasil yang baik. Hasil koefisien Alpha Cronbach menunjukkan semua konstruk memiliki nilai koefisien Alpha melebihi 0,7. Dengan demikian dapat dikatakan instrumen yang dikembangkan dalam penelitian ini sudah memenuhi syarat validitas dan reliabilitas.

Analisis data dilakukan dengan menggunakan MANOVA (Multivariate Analysis of Variance), yakni teknik analisis statistik yang lazimnya digunakan untuk pembandingan beberapa rerata populasi, berdasarkan perbandingan pasangan taksiran varians faktor-faktor tertentu. Pada situasi multivariat, analisis yang merupakan perluasan atau generalisasi dari teknik varians data disebut Analisis Varians Multivariat, dan merupakan teknik analisis data tentang perbedaan pengaruh beberapa variabel terhadap sekelompok variabel kriteria (Suryanto, 1988: 86). Pada penelitian ini analisis MANOVA digunakan untuk menganalisis perbedaan pengaruh variabel kerja part-time terhadap aktivitas belajar dan prestasi akademik mahasiswa baik secara univariat maupun multivariat. Analisis MANOVA menuntut adanya persyaratan normalitas data, dan homogenitas varians kovarians. Oleh karena itu persyaratan tersebut diuji terlebih dahulu sebelum pengujian hipotesis dilakukan.

\section{HASIL DAN PEMBAHASAN}

Penelitian ini menemukan bahwa jumlah mahasiswa bekerja lebih banyak dibandingkan dengan mahasiswa tidak bekerja (lihat Gambar 1). Untuk melihat dampaknya terhadap aktivitas dan prestasi

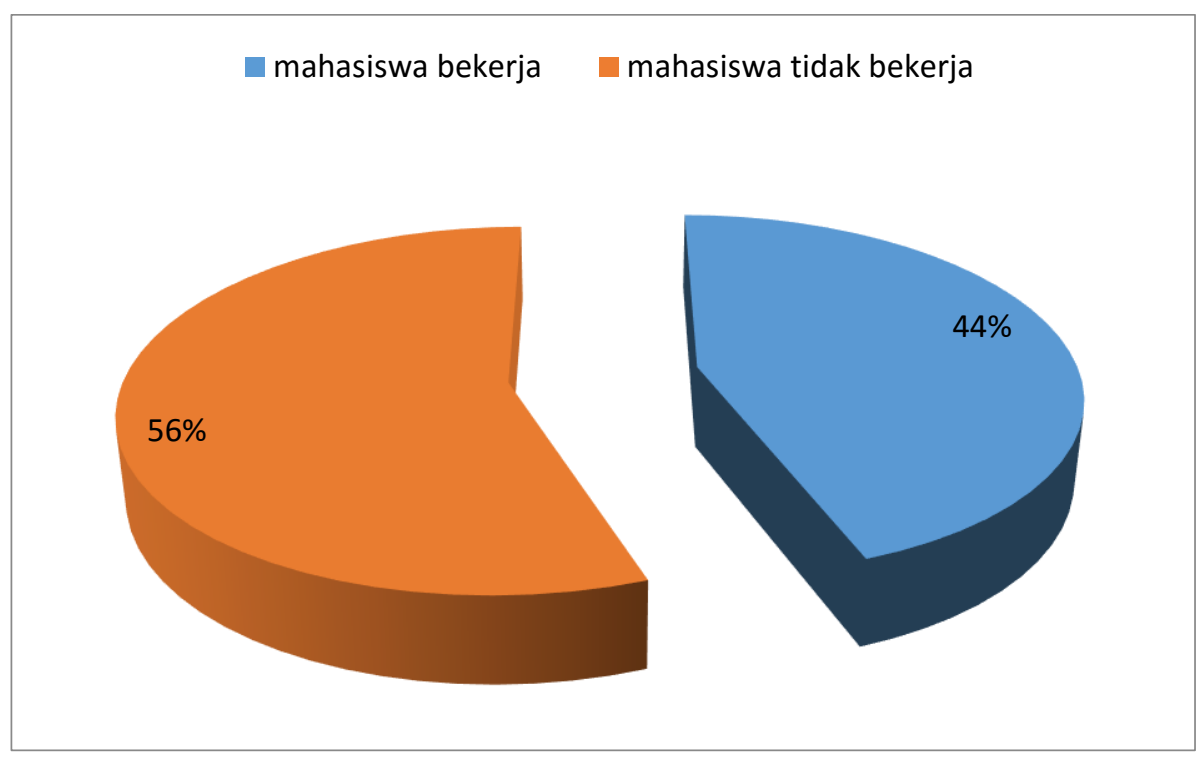

Gambar 1. Status Kerja Mahasiswa 
Tabel 1. Hasil Uji Normalitas

\begin{tabular}{|c|c|c|c|c|}
\hline \multirow{4}{*}{ Variabel } & \multicolumn{4}{|c|}{ Status Kerja } \\
\hline & \multicolumn{2}{|c|}{ Mahasiswa Bekerja } & \multicolumn{2}{|c|}{ Mahasiswa Tidak Bekerja } \\
\hline & Aktivitas & Prestasi & Aktivitas & Prestasi \\
\hline & Belajar & Akademik & Belajar & Akademik \\
\hline Kolmogorov-Smirnov Z & 0,786 & 0,547 & 0,813 & 0,793 \\
\hline$P$ & 0,567 & 0,926 & 0,523 & 0,555 \\
\hline Keterangan & Normal & Normal & Normal & Normal \\
\hline
\end{tabular}

belajarnya dianalisis dengan MANOVA. Untuk dapat menggunakan MANOVA mensyaratkan terpenuhinya asumsi normalitas. Pengujian dilakukan dengan teknik analisis Kolmogorov-Smirnov (K-S). Hasilnya menunjukkan bahwa baik aktivitas belajar maupun prestasi belajar memenuhi syarat normalitas untuk kelompok mahasiswa yang bekerja maupun tidak bekerja (lihat Tabel 1).
Selain itu MANOVA juga mensyaratkan adanya homogenitas varians antar kelompok. Pengujian dilakukan dengan menggunakan uji Levene. Hasilnya menunjukkan bahwa baik variabel aktivitas belajar maupun prestasi belajar memiliki varians yang homogen (lihat Tabel 2). Dengan demikian seluruh persyaratan sudah terpenuhi untuk dianalisis dengan menggunakan MANOVA.

Tabel 2. Hasil Uji Homogenitas

\begin{tabular}{lccc}
\hline \multicolumn{1}{c}{ Variabel } & F & Nilai Sig. & Ket. \\
\hline Aktivitas_Belajar & 0,040 & 0,842 & Homogen \\
Prestasi_Akademik & 0,566 & 0,453 & Homogen \\
\hline
\end{tabular}

Analisis statistika MANOVA juga membutuhkan syarat matriks varians kovarians yang homogen. Untuk menguji syarat ini dapat dipergunakan statistik uji Box-M. Hasilnya menunjukkan bahwa nilai Box's $M$ sebesar 1,722 dengan $F=0,568$ dan $p=0,636$. Oleh karena nilai $p$ lebih dari 0,05 dapat disimpulkan bahwa matriks varians dan kovarians bersifat homogen.
Hasil uji multivariat menunjukkan bahwa ada pengaruh yang signifikan kerja part-time terhadap aktivitas belajar dan prestasi akademik mahasiswa. Hal tersebut ditunjukkan dengan nilai dari uji multivariat Hotteling's trace sebesar 11,884 $p<0,001$. Dengan demikian, akibat adanya double peran yang dimiliki mahasiswa dapat

Tabel 3. Pengujian Univariat

\begin{tabular}{llcc}
\hline \multicolumn{1}{c}{ Variabel } & Status Mahasiswa & Rata-rata & F \\
\hline Aktivitas Belajar & Kerja Part-time & 2,36 & $\left.11,064^{*}\right)$ \\
& Tidak Bekerja & 2,52 & \\
\hline Prestasi Akademik & Kerja Part-time & 3,41 & $\left.16,316^{*}\right)$ \\
& Tidak Bekerja & 3,51 & \\
\hline${ }^{*}$ signifikan & &
\end{tabular}

*) signifikan pada 0,01 
berdampak pada aktivitas dan prestasi belajarnya.

Hasil uji univariate juga menemukan bahwa aktivitas belajar mahasiswa yang bekerja part-time cenderung lebih rendah daripada mahasiswa yang tidak bekerja. Hasil pengujian ditemukan nilai $F$ sebesar 11,064 dengan $p<0,01$ (lihat Tabel 3). Penelitian ini menemukan bahwa kerja part-time berdampak negatif terhadap aktivitas belajar mahasiswa. Temuan ini mendukung hasil penelitian sebelumnya yang menemukan bahwa jumlah jam kerja berdampak negatif terhadap aktivitas belajar termasuk kehadirannya dalam perkuliahan (Warren, et.al., 2000; Curtis \& Shani, 2002). Akibatnya aktivitas belajar mahasiswa menjadi berkurang secara signifikan karena sudah banyak yang tersita untuk bekerja. Mahasiswa yang bekerja harus dapat membagi waktu dan tanggung jawab terhadap komitmen dari kedua aktivitas tersebut. Hal inilah yang membuat mahasiswa menghabiskan sebagian waktu, energi serta tenaga, ataupun pikirannya untuk bekerja. Kondisi tersebut membuat mahasiswa kesulitan dalam mengatur atau membagi waktu antara bekerja dan kuliah, sehingga aktivitas mereka bertambah dan cenderung mengabaikan tugasnya sebagai seorang mahasiswa untuk belajar serta mengerjakan tugas-tugas yang diberikan oleh dosen. Mahasiswa yang tidak dapat mengatur waktu dengan baik dan karena faktor-faktor lain seperti efikasi diri dari mahasiswa, motivasi belajar mahasiswa baik itu secara rohani maupun teknisnya penurunan konsentrasi mahasiswa dalam mengikuti pembelajaran pada mahasiswa yang bekerja sehinggga kerja part-time berpengaruh secara signifikan terhadap aktivitas belajar mahasiswa.

Penelitian ini juga menguji perbedaan prestasi akademik antara mahasiswa yang bekerja part-time dengan mahasiswa yang tidak bekerja. Hasil pengujian sebagaimana terlihat pada Tabel 3 diperoleh nilai F sebesar 16,316 dengan $p<0,01$. Hal ini berarti ada perbedaan prestasi akademik ditinjau dari status kerja mahasiswa. Mahasiswa yang bekerja part-time memiliki prestasi akademik yang lebih rendah dibandingkan dengan mahasiswa yang tidak bekerja. Dengan demikian, kerja part-time di kalangan mahasiswa berdampak negatif terhadap prestasi akademiknya.

Temuan ini mendukung hasil penelitian lain yang menemukan adanya dampak negatif kerja part-time terhadap prestasi belajar (Singh, 1998; Quirk, et.al., 2001). Lebih jauh lagi penelitian lain menemukan bahwa jumlah jam kerja part-time juga berpengaruh negatif terhadap prestasi akademik (Salamonson \& Andrew, 2006; Rochford, 2009). Hal ini mengindikasikan bahwa akibat adanya kerja part-time, fokus mahasiswa untuk belajar menjadi terpecah. Waktu mereka untuk belajar akan tersita untuk persiapan kerja. Hal ini sesuai dengan temuan Pujiyanto (2005) yang menyebutkan bahwa mahasiswa yang melakukan kuliah sambil bekerja lebih memfokuskan diri untuk bekerja dibandingkan belajar dan berdampak pada penurunan prestasi belajar.

\section{SIMPULAN}

Penelitian ini menyimpulkan bahwa secara simultan mahasiswa bekerja memiliki dampak yang signifikan terhadap aktivitas dan prestasi belajar mereka. Hal ini 
ditunjukkan dengan uji multivariat Hotteling's trace sebesar 11,884 dan signifikansi pada 0,001 .

Secara parsial penelitian ini juga menemukan bahwa mahasiswa bekerja berpengaruh secara signifikan terhadap aktivitas belajar. Aktivitas belajar mahasiswa yang tidak bekerja lebih tinggi dibandingkan aktivitas belajar mahasiswa yang bekerja. Selain itu mahasiswa bekerja berpengaruh secara signifikan terhadap prestasi akademik. Prestasi akademik mahasiswa bekerja cenderung lebih rendah dibandingkan prestasi akademik mahasiswa yang tidak bekerja.

Temuan ini menunjukkan bahwa sebagai mahasiswa yang ingin bekerja sambil kuliah hendaknya mempertimbangkan secara matang apakah mampu membagi waktu dan tenaga dengan baik sehingga tidak melalaikan kewajiban utamanya sebagai seorang mahasiswa. Selain itu harus mempertimbangkan adanya pengaruh negatif yang ditimbulkan akibat bekerja yakni mengganggu kelancaran perkuliahan. Hasil penelitian diharapkan dapat memberikan gambaran kepada mahasiswa mengenai mahasiswa yang kuliah sambil bekerja, ataupun hal-hal yang berpengaruh terhadap aktivitas belajar dan prestasi akademik mahasiswa yang kuliah sambil bekerja (kerja part-time). Oleh karena itu kepada seluruh mahasiswa untuk lebih memperhatikan pembagian waktu kalau memilih harus bekerja agar tidak mengganggu aktivitas belajar dan prestasi akademiknya.

\section{DAFTAR PUSTAKA}

Daulay, S.F. (2009). "Perbedaan Self regulated Learning antara Mahasiswa yang Bekerja dan yang Tidak Bekerja", Skripsi. Dipublikasikan: Universitas Sumatera Utara.

Dudija, N. (2011) Perbedaan Motivasi Menyelesaikan Skripsi Antara Mahasiswa yang Bekerja dengan Mahasiswa yang Tidak Bekerja. Humanitas, 8(2), 195-206.

Hipjillah, A. \& Badriyah, N. (2015). Mahasiswa Bekerja Paruh Waktu; Antara Konsumsi dan Prestasi Akademik (Studi Pada Mahasiswa Bekerja Paruh Waktu di Uno Board Game Cafe). Jurnal Ilmiah Mahasiswa Fakultas Ekonomi dan Bisnis, $3(2)$,

Metriyana, M. (2014). "Studi Komparatif Pengaruh Motivasi, Perilaku Belajar, SelfEfficacy dan Status Kerja terhadap Prestasi Akademik antara Mahasiswa Bekerja dan Mahasiswa Tidak Bekerja", Skripsi. Dipublikasikan: Universitas Diponegono, Semarang.

Purwanto, H., Syah, N., \& Rani, I.G. (2013). "Perbedaan Hasil Belajar Mahasiswa yang Bekerja dengan Tidak Bekerja Program Studi Pendidikan Teknik Bangunan Jurusan Teknik Sipil FT-UNP", Jurnal CIVED ISSN 2302-334. Dipublikasikan: Universitas Negeri Padang.

Quirk, K.J., Keith, T.Z. \& Quirk, J.T. (2001). Employment during high school and student achievement: longitudinal analysis of national data. Journal of Educational Research. 95(1), 4-10.

Salamonson, Y. \& Andrew, S. (2006). Academic performance in nursing students: influence of part-time employment, age and ethnicity. Journal of Advanced Nursing. 55(3), 342-351.

Singh, K. (1998). Part-Time Employment in High School and Its Effect on Academic Achievement. The Journal of Educational Research, 91(3), 131-139.. 
Rochford, C, Connolly, M. \& Drennan, J. (2009). Paid part-time employment and academic performance of undergraduate nursing students. Nurse Education Today, 29, 601-606.

Warren, J.R., LePore, P.C., Mare, R.D., (2000). Employment during high school: consequences for students' grades in academic courses. American Educational Research Journal, 37(4), 943-969.

Curtis, S. \& Shani, N. (2002). The Effect of Taking Paid Employment During Termtime on Students' Academic Studies. Journal of Further and Higher Education, 26(2), 129-138.

Robert, P. \& Saar, E. (2012). Learning and Working: The Impact of the 'Double
Status Position' on the Labour Market Entry Process of Graduates in CEE Countries. European Sociological Review, 28(6), 742-754.

Suryanto. (1988). Metode Statistika Multivariat. Jakarta: Departemen Pendidikan dan Kebudayaan Direktorat Jenderal Pendidikan Tinggi P2LPTK.

Van der Meer, P. \& Wielers, R. (2001). The increased labour market participation of Dutch students. Work, Employment and Society, 15, 55-71.

Lenaghan, J.A. \& Sengupta, K. (2007). Role conflict, role balance and affect: A model of well-being of the working student. Journal Behavioral Applied Management, 9(1), 88-109. 